\title{
Forward Model Resistivitas DC Dengan Metode Elemen Hingga dan Pendekatan Potensial Sekunder Berbasis Python
}

\author{
M.Februarianto(a) ${ }^{*}$, A. D. Garnadi (b), M. N. Indro (c), M.T. Julianto(b), S. Nurdiati(b)
}

(a) Dept. Matematika, FMIPA, Institut Pertanian Bogor, Bogor 16680

*m.februarianto@gmail.com

(b) Dept. Matematika, FMIPA, Institut Pertanian Bogor, Bogor 16680

(c) Dept. Fisika, FMIPA, Institut Pertanian Bogor

Bogor 16680

\begin{abstract}
Metode survei resistivitas DC (Direct Current) adalah suatu metode eksplorasi geofisika untuk mengetahui distribusi resistivitas bawah permukaan dari suatu struktur. Metode ini dilakukan dengan menggunakan dua pasang elektroda di permukaan, dimana sepasang elektroda (A - B) berperan sebagai elektroda arus untuk menginjeksikan arus ke bawah permukaan dan pasangan elektroda lainnya (M - N) digunakan untuk menghitung beda potensial yang timbul akibat arus dari elektroda A-B. Beda potensial yang terjadi dapat dinyatakan dengan persamaan differensial parsial (PDP) tipe Poisson.

Hasil pengukuran beda potensial kemudian digunakan untuk menghitung nilai apparent resistivity yang merepresentasikan nilai resistivitas di bawah permukaan. Nilai apparent resistivity bergantung pada jenis konfigurasi elektroda yang digunakan, intensitas arus, dan beda potensial yang ditimbulkan. Dalam prakteknya, metode survei resistivitas DC seringkali didukung oleh pemodelan geofisika berupa forward model. Forward model dapat membantu dalam interpretasi data distribusi resistivitas sehingga diperoleh pemahaman yang lebih baik mengenai struktur di bawah permukaan.
\end{abstract}

Penelitian ini menggunakan Esys Escript sebagai alat untuk menyelesaikan permasalahan forward model untuk kasus domain tiga dimensi (3D). Escript merupakan suatu solver untuk metode elemen hingga (MEH) yang dikembangkan dalam bahasa Python. Escript dapat digunakan untuk menyelesaikan berbagai PDP secara numerik, salah satunya adalah PDP tipe Poisson. Untuk menyelesaikan PDP tipe Poisson, Escript menggunakan fungsi Dirac Delta sebagai source term dan mixed boundary condition sebagai syarat batas dalam pemodelan. Masalah singularitas yang terjadi yang timbul akibat penggunaan fungsi Dirac Delta akan diatasi dengan pendekatan potensial sekunder.

Pada kesempatan kali ini, akan diperlihatkan beberapa contoh kasus survey geolistrik sintetis yang akan diselesaikan secara numerik oleh Escript. Survey geolistrik yang digunakan mencakup konfigurasi Dipole-Dipole, Wenner, dan Schlumberger.

Keywords: Survey Geolistrik, Escript, Metode Elemen Hingga, Python, Persamaan Differensial Parsial.

\section{PENDAHULUAN}


Metode Survey resistivitas Direct Current (DC) merupakan suatu metode survey geofisika untuk mengetahui distribusi nilai resistivitas di bawah permukaan bumi secara spasial. Nilai resistivitas tersebut dapat digunakan untuk menggambarkan kondisi bawah permukaan dari suatu area, bagaimana distribusi batuan/metal di bawah permukaan atau bahkan untuk mendeteksi adanya suatu anomali pada kedalaman tertentu di dalam lapisan tanah/batuan. Metode ini memegang peranan penting dalam bidang geofisika dan teknik lingkungan.

Mudahnya pengoperasian alat survey, biaya operasional yang tidak terlalu besar, dan banyaknya dukungan tools komputasi yang semakin berkembang menyebabkan metode survey resistivitas DC menjadi metode yang sering dipalao untuk mengetahui kondisi fisis sebaran resistivitas bawah permukaan dari suatu daerah. Nilai resistivitas di bawah permukaan bumi akan bergantung pada sifat fisika dan kimiawi dari suatu batuan atau material yang terdapat di bawah permukaan. Binley dan Kemna (2015) menyatakan litologi batuan, zat kimia yang mengisi pori-pori dari batuan, dan konsentrasi air pada tanah akan mempengaruhi sifat fisika dan kimia yang pada akhirnya akan berpengaruh pada nilai distribusi resistivitas di area tersebut..

Terdapat tiga bagian penting dari survey resistivitas DC, ketiga bagian tersebut adalah pengumpulan data dari survey lapangan, forward modelling, dan proses inversi untuk mengetahui resistivitas sebenarnya dari area survey. Penelitian kali ini akan berfokus pada bagian forward modelling yang merupakan salah satu bagian penting dari survey resistivitas DC. Tools yang akan digunakan kali ini adalah Esys Escript yang merupakan suatu solver berbasis Python untuk Persamaan Differensial Parsial (PDP), Gmsh sebagai tools untuk finite element meshing, dan modul matplotlib dari Python sebagai alat bantu untuk menampilkan hasil komputasi. Paper ini akan berusaha membahas mengenai tools yang digunakan untuk modeling dan persamaan matematis yang digunakan.

\section{METODE SURVEY RESISTIVITAS DC}

\section{Konsep Dasar Resistivitas DC}

Pada survey resistivitas DC, digunakan dua pasang elektroda (quadrapole) yang memiliki fungsi yang berbeda-beda untuk tiap pasang elektroda. Terdapat sepasang elektroda arus (elektroda A dan B) dan sepasang elektroda lainnya (elektroda M dan N) yang berfungsi untuk mengukur beda potensial. Elektroda $A$ dan $B$ digunakan untuk menginjeksikan arus listrik ( $I$ pada permukaan bumi yang akan menimbulkan beda tegangan ( $V$ ) yang dapat diukur diantara elektroda $\mathrm{M}$ dan $\mathrm{N}$. 
Pada suatu domain 3-D isotropik $(\Omega)$, distribusi potensial didapat sebagai solusi dari PDP tipe Poisson. PDP yang diselesaikan merupakan turunan dari kontinuitas rapat medan arus yang dinyatakan oleh persamaan (1).

$$
\nabla \cdot J^{e}=0
$$

dengan $l^{e}=\sigma E$. $l^{c}$ merupakan nilai konduksi densitas arus di permukaan, $\sigma$ adalah nilai konduktivitas material $(1 / \rho)$, dan Eadalah intensitas medan listrik $(\nabla u)$. Dari persamaan [1] kita bisa mendapatkan persamaan Poisson yang dinyatakan pada persamaan (2).

$$
\nabla \cdot(\sigma \nabla u)=\nabla \cdot J^{g}
$$

Persamaan (2) harus memenuhi syarat batas Neumann di permukaan (daerah interaksi tanah-udara) dan syarat batas Dirichlet pada sisi domain lainnya. Syarat batas Neumann dan Dirichlet masing-masing dinyatakan oleh persamaan (3) dan (4). Konsep domain dari daerah penelitian dan syarat batas tersebut digambarkan pada Gambar (1).

$$
\begin{aligned}
& \frac{\partial u}{\partial n}=0 \\
& u=0
\end{aligned}
$$




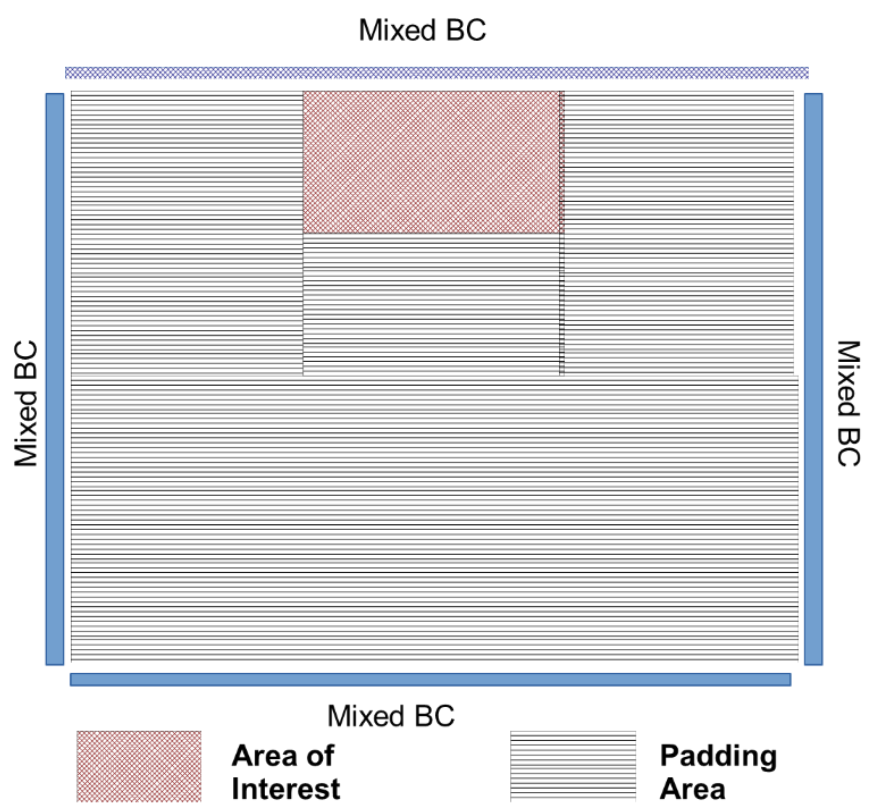

Gambar 1 Konsep domain model resistivitas

Untuk kasus sumber arus tunggal di titik $x_{o}$ dan dilakukan pengukuran potensial listrik pada titik $x_{1}$, maka suku $l^{\Xi}$ dapat dinyatakan oleh persamaan (5).

$$
\nabla \cdot J^{s}=\frac{-\partial \varphi_{s}}{\partial t} \delta\left(x-x_{0}\right)=-I \delta\left(x-x_{0}\right)
$$

dengan $\nabla=\frac{\partial}{\partial x}+\frac{\partial}{\partial y}+\frac{\partial}{\partial z}, q_{\varepsilon}$ adalah densitas muatan arus, $I$ adalah nilai intensitas arus listrik, dan Eadalah fungsi dirac delta. Pada survey resistivitas DC yang menggunakan source sebanyak-N yang tersebar pada lokasi $x_{i}$, maka persamaan (3) akan menjadi persamaan (6).

$$
-\nabla \cdot(\sigma \nabla u)=\Sigma_{s=1}^{N_{s}} I_{i} \delta x_{s}=Q
$$

Penggunaan elektroda arus bermuatan positif $(+)$ dan negative $(-)$ dengan besaran arus $I_{i}^{+}=-I_{i}^{-}$pada survey resistivitas DC menyebabkan persamaan (6) menjadi :

$$
Q=\sum_{s=1}^{N s}\left(\boldsymbol{I}_{i}^{+} \delta_{x_{s}^{+}}+\boldsymbol{I}_{i}^{-} \delta_{x_{s}^{-}}\right)
$$

\section{Konfigurasi Elektroda Survey}

Metode survey resistivitas DC memiliki beberapa pengaturan letak elektroda arus dan potensial yang berbeda (Gambar 2). Perbedaan letak elektroda pada setiap konfigurasi akan mempengaruhi sensitivitas survey yang akan berpengaruh pada distribusi nilai resistivitas hasil survey/forward modelling. Akibat adanya variasi sensitivitas tersebut, maka diperlukan pemilihan konfigurasi elektroda yang tepat sesuai dengan tujuan survey 
resistivitas (kedalaman investigasi, resolusi vertikal, kekuatan sinyal, dan untuk vertical sounding/lateral profiling). Tabel (1) menunjukkan perbandingan antara tiga konfigurasi elektroda yang sering digunakan (Wenner, Schlumberger, Dipole-dipole) yang merujuk pada hasil penelitian Binley (2015).

Tabel 1 Perbandingan konfigurasi elektroda terhadap sensitivitas parameter suvey

\begin{tabular}{|c|c|c|c|}
\hline Parameter & Wenner & Schlumberger & Dipole-Dipole \\
\hline Kedalaman Investigasi & Rendah & Sedang & Tinggi \\
\hline Resolusi Vertikal & Tinggi & Sedang & Rendah \\
\hline $\begin{array}{c}\text { Kekuatan Sinyal } \\
\text { Kecocokan untuk Vertical } \\
\text { Sounding } \\
\text { Kecocokan untuk lateral } \\
\text { profilling }\end{array}$ & Tinggi & Sedang & Rendah \\
\cline { 2 - 4 } & Sedang & Tinggi & Rendah \\
\hline
\end{tabular}
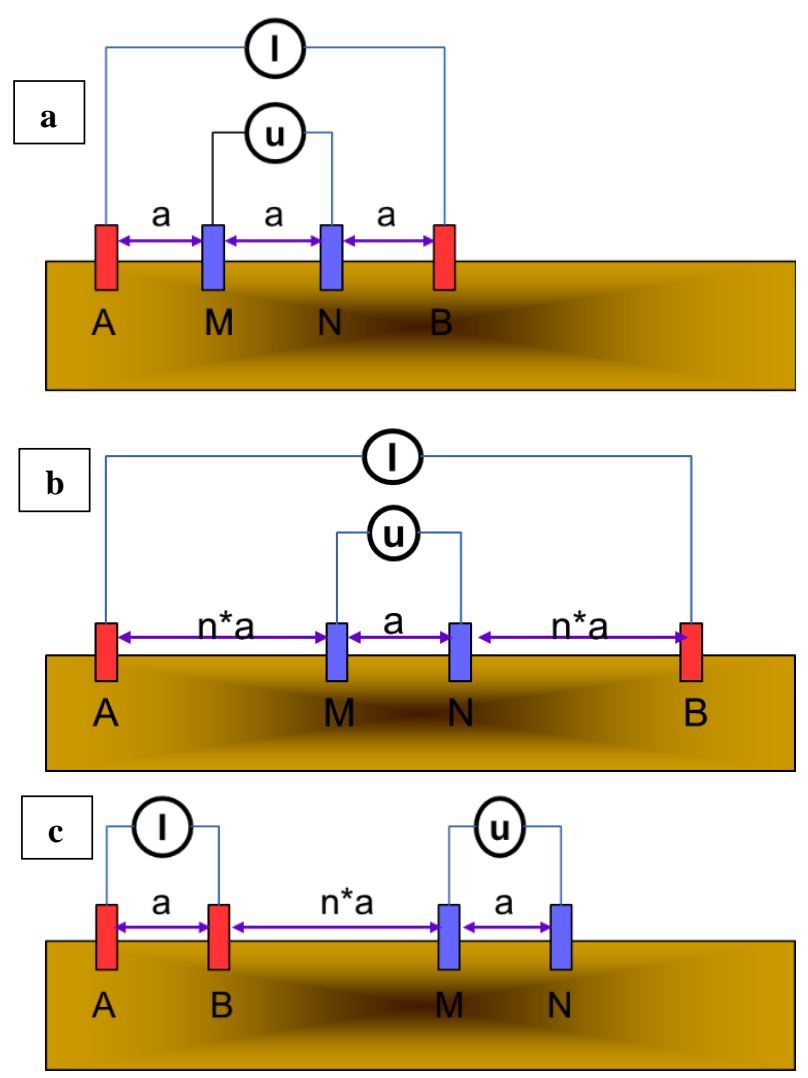

Gambar 2 Konfigurasi elektroda survey: (a)Wenner, (b) Schlumberger, dan (c) Dipoledipole 
Pada konfigurasi elektroda di atas, a merupakan jarak antar elektroda dan $n$ merupakan bilangan integer $(n=1,2,3, . ., n)$. Untuk menghitung nilai potensial pada pasangan elektroda $\mathrm{M}$ dan $\mathrm{N}$ di titik manapun, digunakan persamaan (7).

$V=\frac{d \rho}{2 \pi r c^{+}}-\frac{d \rho}{2 \pi r c^{*}}$

Pada persamaan (7), $r c^{+}$merupakan jarak dari elektroda positif $\left(\mathrm{C}^{+}\right)$dan $r c^{-}$merupakan jarak dari elektroda negatif $\left(\mathrm{C}^{-}\right)$. Pada suvey resistivitas $\mathrm{DC}$ dengan quadrapole, persamaan (7) perlu memperhitungkan jarak elektroda $A$ dan $B$ dari $C^{+}$dan $C^{-}$. Sehingga persamaan (7) menjadi persamaan (8).

$\Delta V=\frac{I \rho}{2 \pi}\left(\frac{1}{A M}-\frac{1}{B M}-\frac{1}{A N}+\frac{1}{B N}\right)$

Dalam forward model, nilai distribusi resistivitas dinyatakan oleh nilai resistivitas semu $\left(\rho_{a}\right)$ yang mengasumsikan bumi bersifat homogen dan datar. Nilai $\rho_{a}$ untuk suatu forward modeling dapat dihitung dengan persamaan berikut:

$P_{a}=\frac{k a V}{I}$

dengan $k$ merupakan faktor geometri yang bergantung pada jarak antar elektroda di tiap konfigurasi. Nilai $k$ dinyatakan oleh persamaan (10).

$k=\frac{2 \pi}{\left(\frac{1}{A M}-\frac{1}{B M}-\frac{1}{A N}+\frac{1}{B N}\right)}$

\section{TOOLS}

\section{Gmsh}

Program Gmsh (Geuzaine dan Remacle, 2009) merupakan suatu program finite element mesh (FEM) generator yang digunakan untuk mempersiapkan domain model dalam penelitian kali ini. Gmsh memungkinkan pengguna untuk mendesain geometri domain model yang akan digunakan melalui script ataupun Graphical User Interface (GUI). Dalam pembuatan domain model, terdapat beberapa parameter penting yang perlu diperhatikan, parameter-parameter tersebut adalah :

- Nodes wajib diberikan pada kordinat yang akan digunakan sebagai lokasi elektroda survey 
- Ukuran elemen di dekat elektroda dan pada daerah kajian (area of interest) harus lebih rapat dibandingkan dengan elemen di luar daerah kajian (padding area)

Untuk membuat domain model melalui Gmsh, diawali dengan membuat desain geometri 3-D dari daerah yang akan dimodelkan. Desain 3-D tersebut perlu mencakup daerah kajian (berupa lokasi elektroda dan posisi material di bawah permukaan) dan padding area agar nilai di batas domain tidak mempengaruhi keakuratan model.

\section{Esys ESCRIPT}

Esys Escript (Escript) merupakan suatu modul PDP solver yang dikembangkan dalam bahasa Python yang memungkinkan pengguna mengimport escript sebagai modul Python untuk menyelesaikan PDP secara numerik. Escript dikembangkan oleh Centre for Geoscience Computing, University of Queensland. Escript memberikan kebebasan bagi pengguna untuk menyelesaikan berbagai permasalahan di bidang geofisika (gravity model, magnetotelluric, DC resistivity) tanpa direpotkan dengan membuat kode berbasis Python dari awal. Meskipun demikian, Escript tetap memungkinkan pengguna untuk membangun kodenya sendiri dari dasar. Escript dirancang untuk dapat menyelesaikan permasalahan PDP dalam mesh 2-D dan 3-D, baik structured maupun unstructured.

Dalam aplikasinya di forward modeling untuk survey resistivitas DC, Escript menggunakan secondary field approach dengan unstructured mesh (Schaa, et. al., 2016). Pada pendekatan ini, nilai potensial primer dan sekunder akan dihitung untuk topografi bumi datar dan bervariasi. Escript akan berusaha menyelesaikan permasalahan singularitas yang timbul akibat penggunaan fungsi Dirac Delta pada persamaan (7). Lowry et al (1989) menyatakan jika permasalahan singularitas yang muncul pada forward model, dapat diatasi dengan memperkecil ukuran mesh di dekat elektroda sumber (source) dan dengan membagi potensial total menjadi potensial primer dan sekunder (Persamaan 11a) dan juga nilai konduktivitas menjadi konduktivitas primer dan konduktivitas anomali/sekunder (Persamaan 11b).

$$
\begin{aligned}
& u=u^{p}+u^{s} \\
& \sigma=\sigma^{p}+\sigma^{s}
\end{aligned}
$$

Dengan menggunakan pendekatan potensial dan konduktivitas primer dan sekunder, maka persamaan (6) akan menjadi :

$$
\begin{aligned}
-\nabla \cdot\left(\sigma^{p} \nabla u^{p}\right) & =Q \\
\nabla \cdot\left(\sigma \nabla u^{s}\right) & =\nabla \cdot\left(\left(\sigma^{p}-\sigma\right) \nabla u^{p}\right)
\end{aligned}
$$

Escript akan menyelesaikan persamaan (12a) dan (12b) secara numerik dengan 
mengaplikasikan syarat batas yang digabung dengan weak form. Weak form didapatkan dengan memberikan bobot $(w)$ untuk persamaan (12a) dan (12b) yang kemudian diintegralkan untuk keseluruhan area domain $(\Omega)$ sehingga didapat persamaan (13a) untuk kasus potensial primer dan persamaan (13b) untuk kasus persamaan sekunder.

$$
\begin{aligned}
-\int_{\Gamma} d \Gamma \sigma^{p} \omega \mathbf{n} \cdot \nabla u^{p}+\int_{\Omega} d \Omega \sigma^{p} \nabla \omega \cdot \nabla u^{p} & =\int_{\Omega} d \Omega \omega Q \\
-\int_{\Gamma} d \Gamma \sigma \omega \mathbf{n} \cdot \nabla u^{s}+\int_{\Omega} d \Omega \sigma \nabla \omega \cdot \nabla u^{s} & =\int_{\Gamma} d \Gamma\left(\sigma^{p}-\sigma\right) \omega \mathbf{n} \cdot \nabla u^{p}+\int_{\Omega} d \Omega\left(\sigma^{p}-\sigma\right) \nabla \omega \cdot \nabla u^{p}(13 \mathrm{~b})
\end{aligned}
$$

Untuk menyelesaikan persamaan (13a) dan (13b) diberikan syarat batas (boundary condition) berupa udara yang bersifat non-konduktif $(n \cdot \nabla u=0)$ dan nilai potensial yang terdisipasi akibat domain model yang diasumsikan sangat besar. Lowry et al (1989) dalam Schaa et al (2016) menyatakan syarat batas tersebut dalam persamaan matematik berikut:

Pada $\Gamma^{\mathrm{N}}$

$$
\begin{aligned}
& \sigma \mathbf{n} \cdot \nabla u^{s}=0 \\
& \sigma^{p} \mathbf{n} \cdot \nabla u^{p}=0 \\
& \left(\sigma^{p}-\sigma\right) \mathbf{n} \cdot \nabla u^{p}=0
\end{aligned}
$$

Pada $\Gamma^{\mathrm{D}}$

$$
u=0
$$


PEMBAHASAN

\section{Desain geometri model}
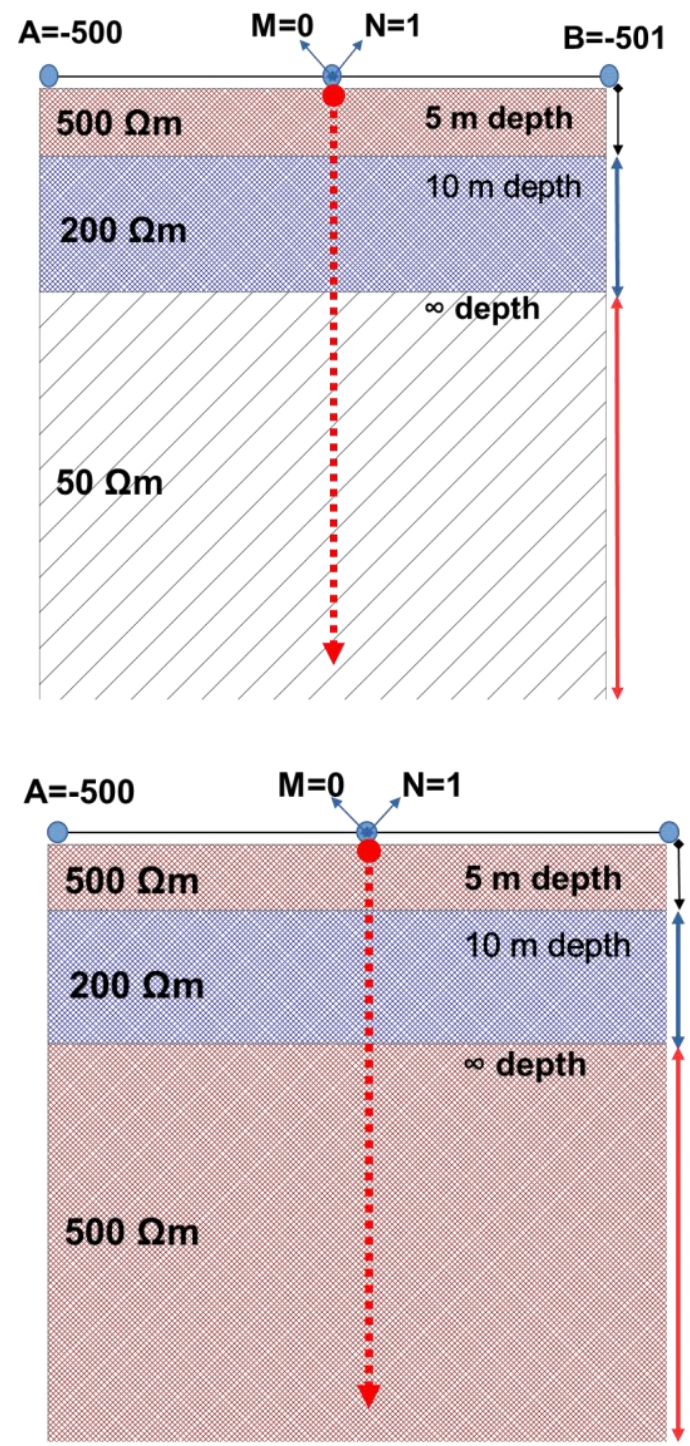

\section{Setting Elektroda}

\section{UCAPAN TERIMA KASIH}

Penelitian ini dibiayai oleh Direktorat Riset dan Pengabdian Masyarakat Direktorat Jenderal Penguatan Riset dan Pengembangan Kementrian Riset, Teknologi, dan Pendidikan Tinggi, PUPTIPB dengan kontrak Nomor 083/SP2H/PL/Dit.Litabmas/II/2015, serta Nomor: 079/SP2H/LT/DRPM/II/2016. 


\section{REFERENSI}

Binley, A., 2015, Tools and Techniques: DC Electrical Methods, In: Treatise on Geophysics, 2nd Edition, G Schubert (Ed.), Elsevier., Vol. 11, 233-259, doi:10.1016/B978-0-444-53802-4.00192-5.

Binley, A., dan Kemna, A., 2005. DC Resistivity and induced polarization methods. Chap. DC Resistivity, pages 129-156 of: Rubin, Y., dan Hubbard, S.S (eds), Hydrogeophysics. N.Y: Springer

Lowry T, Allen M dan Shive P N, 1989, Singularity removal : a refinement of resistivity modeling techniques, Geophysics 54: 766-74

Schaa, R., L. Gross, dan J. du Plessis, 2016, PDE-based geophysical modelling using finite elements: examples from 3D resistivity and 2D magnetotellurics, J. Geophys. Eng. 13(2016) S59-73

Schaa, R., L. Gross, dan J. du Plessis, 2015, Paralellized Three-Dimensional resistivity inversion using finite elements and adjoint state method - initial results, EGU20154402 